\title{
The Prediction of Preference for Unfamiliar Urban Places
}

\author{
Thomas R. Herzog \\ Grand Valley State Colleges \\ Stephen Kaplan and Rachel Kaplan \\ The University of Michigan
}

Preferences for unfamiliar urban environments were studied as a function of urban categories, viewing time, and four predictor variables: complexity, coherence, identifiability, and mystery. A nonmetric factor analysis of the preference ratings for the longest viewing-time condition yielded five dimensions: Contemporary Life, Alley/Factory, Urban Nature, Unusual Architecture, and Older Buildings. The five categories differed significantly in preference, with Urban Nature by far the most preferred and Alley/Factory distinctly disliked. The combination of low coherence and high complexity characterizes the least liked Alley/Factory category, while the role of mystery in the urban setting is highlighted by the most preferred Urban Nature category. The results point to various ways in which the urban environment could be more responsive to people's preferences.

Social scientists have devoted considerable effort toward understanding the urban experience. Some see the city as a source of too much unwanted stimulation (Milgram, 1970), while others deplore its lack of diversity (Parr, 1965). Since the pioneering work of Lynch (1960), much research has concentrated on exploring the composition and organization of people's cognitive maps of their urban environments (e.g., Downs \& Stea, 1973, 1977). Less attention has been paid to the emotional-evaluative aspects of such maps (Craik, 1973). Presumably preference, as well as location, ap-

This research was supported in part by a grant from the Grand Valley State Colleges Research Development Fund to Thomas Herzog and in part by the Urban Forestry Unit of the U.S. Forest Service's North Central Experimental Station in a cooperative research agreement with R. Kaplan and S. Kaplan. 
pearance, and function, is included as part of the cognitive representation of urban places. An initial effort to study this issue (Herzog, Kaplan \& Kaplan, 1976) was restricted to familiar urban places and convinced us that the reaction to familiar places constitutes a rather special case. People's reactions were sufficiently stereotyped that they did not even have to look at a slide of the place in question; hearing its name was enough. Thus, the purpose of the present study was to explore urban preference in a context uncontaminated by the influence of familiarity.

A twofold research strategy guided this study. On the one hand, psychology contains a strong tradition of accounting for perception in terms of a categorization process (e.g., Bruner, 1957), a tradition that has carried over into accounts of environmental perception (Appleyard, 1970). Consequently, one aim of this study was to identify content categories that underlie preferences for urban places. Methods for discovering such categories have been described by R. Kaplan (1972), and the approach has been used successfully in the study of preferences for natural environments (S. Kaplan, 1979a). Of course, urban preference categories uncovered in any one study may or may not have generality across different populations or cities. Nevertheless, such categories should provide insight into the bases or criteria used by the particular people studied to structure their particular city in terms of preference.

On the other hand, it should be possible to find predictor variables that are also effective in accounting for environmental preferences. S. Kaplan (1975) describes the twin dangers of having too few predictors to do an adequate job or of having a list of predictors that grows arbitrarily long. The proposed solution is to develop a set of predictors that are related to each other within a systematic theoretical framework. Viewing humans as products of an evolutionary history in which the processing of spatial information was of critical importance, we have attempted to develop such a set of predictor variables (R. Kaplan, 1977; S. Kaplan, 1975, 1979a, 1979b; S. Kaplan \& R. Kaplan, 1978).

In this study, four of these predictor variables were investigated. Two of them involve properties, of a scene that can be assessed rather directly without any need for making inferences. They are the sheer amount of information or the number of elements present in a scene (complexity) and the organization or arrangement of the elements (coherence). The other two predictor variables require making inferences that go beyond the 
information directly present in the scene. They are the sense of familiarity evoked by a scene or the ease of identifying what the scene is about (identifiability) and the extent to which the scene promises further information if the observer could walk deeper into it (mystery).

The precise role of each of these predictor variables in accounting for environmental preference is yet to be determined. Complexity has been marked by theoretical controversy and contradictory findings. R. Kaplan (1975) reviews both. In Herzog et al. (1976), complexity was positively related to preference for several categories of familiar urban scenes. One possible reason for the confusing results involving complexity may be that it interacts with other predictors such as coherence. Informationoverload theory (Milgram, 1970) would suggest that urban categories characterized by the combination of high complexity and low coherence would be strongly disliked. A separate question is whether coherence alone is related to preference within specific urban categories. No research has been directed toward that question. Similarly, identifiability remains largely unexplored as a preference predictor. S. Kaplan (1975) noted that graphics of outdoor scenes that lacked identifiability evoked "anger and hostility" in observers. Herzog et al. (1976) found that ratings of actual familiarity were consistently correlated with preference ratings for urban scenes, but the correlations were negative for some types of scenes. Mystery has been found to be reliably associated with high preference in natural environments ( $R$. Kaplan, 1975). Hence, it might be expected to play a similar role for urban scenes that contain a sizeable nature component.

The major objectives of the study entailed these issues, namely, the categorization of the unfamiliar urban environment and the role of the predictor variables in accounting for preference. A further interest involved the issue of viewing time. A typical viewing of the passing scene is of extremely brief duration (fractions of a second). Thus both brief viewing exposures and relatively longer ones (more characteristic of slide viewings) were used.

\section{METHOD}

\section{Participants}

The sample consisted of 249 introductory psychology students of both sexes at Grand Valley State Colleges. Participation in the study partially 
fulfilled course requirements. Fifteen groups of from nine to 26 participants were run. The first six groups (phase 1) each rated the settings on two of four predictor variables to be described below. These groups included only participants who were unfamiliar with most of the settings. The last nine groups (phase 2) rated the settings for preference.

Since the study dealt with preference for unfamiliar urban places, it was necessary to insure that familiar scenes were not included in phase 2. This was accomplished by a two-step procedure applied to certain data of phase 1. Phase-1 participants were asked to check any scenes they recognized with certainty. First, phase-1 participants who checked more than $10 \%$ of the scenes were eliminated from the study. Then scenes checked by more than $10 \%$ of the remaining participants were eliminated from the study. This procedure resulted in the elimination of six phase- 1 participants and of five scenes. The $10 \%$ criterion was chosen because it was fairly stringent and yet not so severe as to eliminate participants and scenes with only a few checks.

\section{Stimuli}

The settings for phase 1 of the study consisted of 140 color slides of urban scenes from various locations in Michigan's lower peninsula. Since unfamiliar scenes were desired, no settings within an approximate radius of 30 miles from Grand Rapids (the location of the college) were included. An attempt was made to sample as wide a variety of urban scenes as possible but to avoid scenes containing people. Scenes included academic settings, apartment buildings, commercial buildings, factories, alleys, street scenes, residential areas, parks, restaurants, as well as civic and governmental settings. In phase 2 of the study, 70 of the original 140 scenes were used. The method of selecting the phase-2 scenes is described below.

\section{Procedure}

In phase 1 of the study, all participants rated each of the original 140 scenes for two of four predictor variables. All ratings utilized a five-point scale ranging from $1=$ "not at all" to $5=$ "a great deal." The predictor variables were identifiability, coherence, complexity, and mystery. Identifiability was defined as "how easily you can tell what is being depicted... how easy it is to come up with an appropriate verbal description or label for the scene." Coherence was "the extent to which the scene 'hangs together" or contains "repeated elements, textures, and structural factors" that "allow one to predict from one portion of a scene 
to another." A complex scene was one "that contains a lot of elements, regardless of their arrangement." Such a scene promises "further information if only you had more time to look at it from your present vantage point." Mystery referred to "the promise of further information based on a change in the vantage point of the observer" such that the observer is permitted to "walk deeper into the scene." These variables are discussed in more detail by S. Kaplan (1975).

Each of the six phase-1 groups rated a different combination of two predictor variables. Thus, each variable was rated by three groups. Each scene was presented for 15 seconds, and a different random order of presentation was used for each of the six groups. Five practice slides preceded the 140 scenes, and a brief intermission occurred halfway through each session. Final sample sizes for each variable were 48, 52, 57 , and 51 for identifiability, coherence, complexity, and mystery.

Following phase 1 , mean ratings were computed for each scene on each predictor variable. These means were then rank ordered separately for each predictor variable. After familiar scenes had been eliminated, the 70 scenes for phase 2 were selected so as to sample the full range of ratings for each of the four predictor variables.

In phase 2, different groups of participants rated each of the 70 scenes for preference, defined as "how pleasing it is to you, how much you like it," using a five-point scale. The same five practice slides as in phase 1 preceded the 70 scenes, and a brief intermission occurred halfway through each session.

There were four experimental conditions in phase 2 based on the viewing time for each scene. Viewing times were 15 seconds, 20 milliseconds, two consecutive 10-millisecond presentations, or one 10-millisecond presentation. The brief viewing times were achieved by using an electronic shutter mounted in front of the projector lens. Two groups were run in each of the brief viewing-time conditions and three groups in the 15-second condition. The same random order of scene presentation was used for the first group in each condition, and the reverse of that order was used for the last group in each condition. The second group in the 15-second condition received that same order but with its two halves interchanged. The sample sizes for the 15-second, 20-, $2 \times 10$, and 10-millisecond conditions were $74,20,28$, and 23 , respectively. The larger sample in the 15-second condition was used to have a sufficient data base for a nonmetric factor analysis.

\section{RESULTS AND DISCUSSION}

\section{Categorization of Scenes}

It is difficult to deal directly with the question of how people feel about their environment. One the one hand, people often have 
a hard time verbalizing their feelings. On the other hand, if they are provided with descriptors to choose among, one runs the risk of putting words into their mouths. However, these obstacles can be avoided by presenting people with environments and simply asking them how much they like each one. From such data it is possible to infer the underlying bases of their preferences; that is, what sorts of environments they react to as being in the same categories.

To discover the environmental categories that influenced the participants' reactions in this study, the preference ratings of the 70 scenes in the 15 -second condition were subjected to a nonmetric factor analysis, the Guttman-Lingoes Smallest Space Analysis III (Lingoes, 1972). The advantages of the nonmetric approach are discussed by R. Kaplan (1972). It is important to emphasize that scenes rather than verbal descriptors are being grouped by this procedure and that the grouping reflects the pattern of the preference ratings.

The Smallest Space Analysis yielded five dimensions. Dimensional composition was determined by including all scenes with a factor loading greater than .40 on a given dimension and no loading greater than .40 on any other dimension. The only exception involved a scene that was omitted despite its loading of .42. The scene depicted a modern research building and, according to the statistical criteria, should have been included with the other six scenes of the Older Building dimension. It was simply out of place in that group. As R. Kaplan (1974) points out, dimensional composition should also be susceptible to meaningful interpretation. Some scenes from each dimension are shown in Figures 1 through 5 .

The dimension with the greatest number of scenes (18) included student housing, academic buildings, modern apartment buildings, and some commercial establishments (Figure 1). This was named the Contemporary Life dimension.

The second dimension consisted of 11 scenes (Figure 2), including downtown alleys and factories. These scenes communicate a rather desolate feeling by virtue of both their scale and their facelessness. The was named the Alley/Factory dimension.

The third dimension consisted of nine scenes (Figure 3), dominated primarily by trees and green grass. In most cases buildings are visible through the foliage. This was named the Urban Nature dimension. 
THOMAS R. HERZOG, STEPHEN KAPLAN AND RACHEL KAPLAN
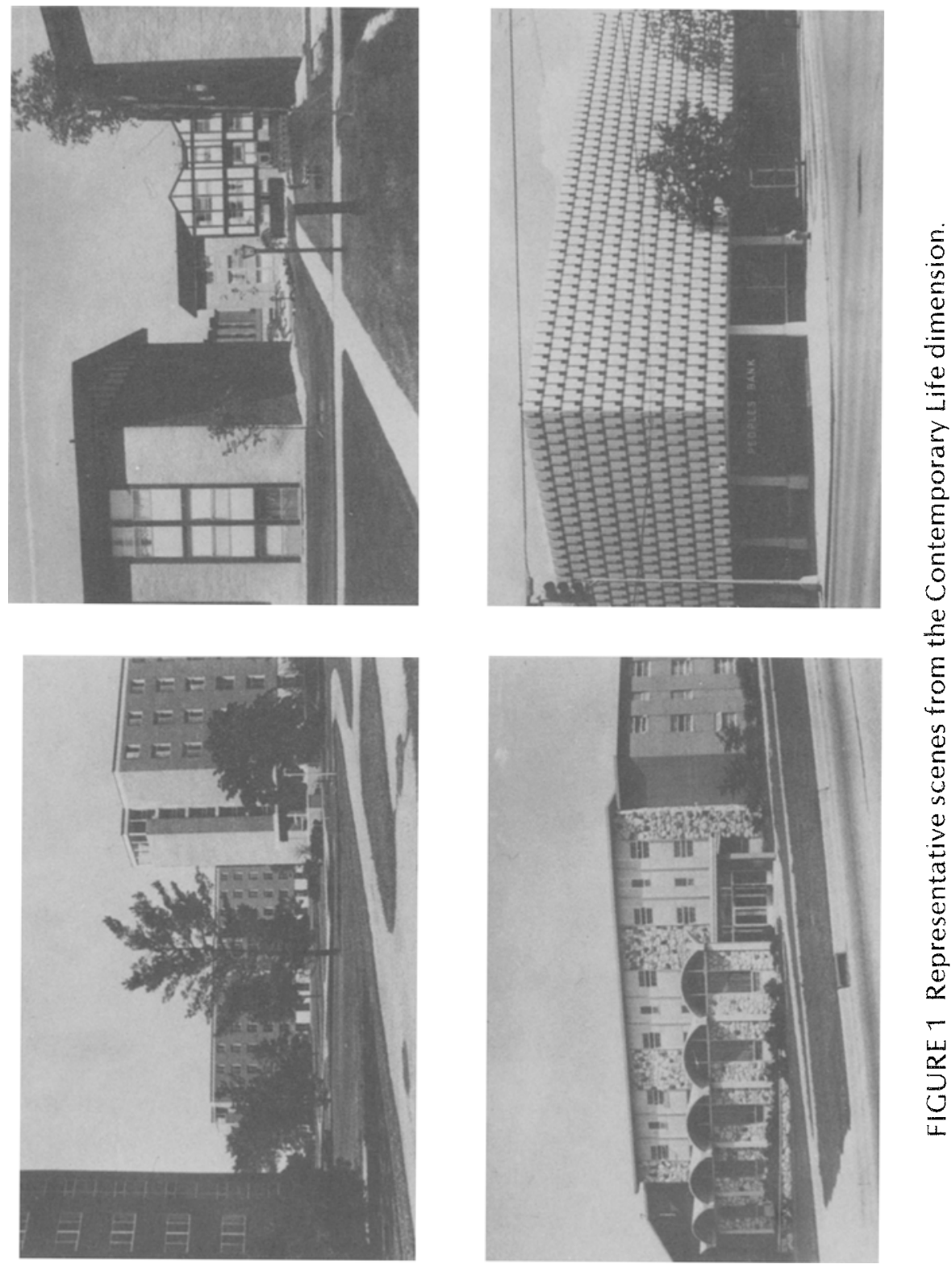
POPULATION AND ENVIRONMENT
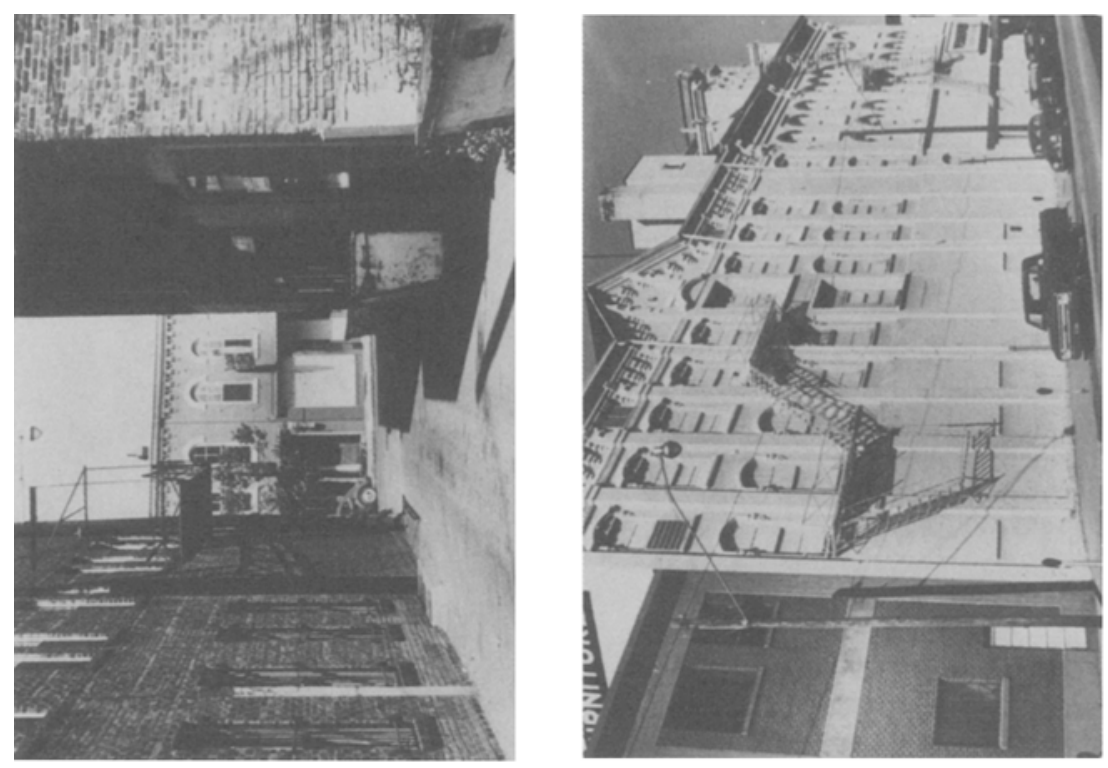

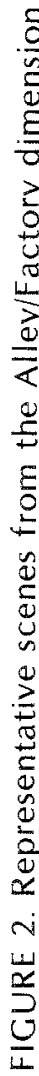
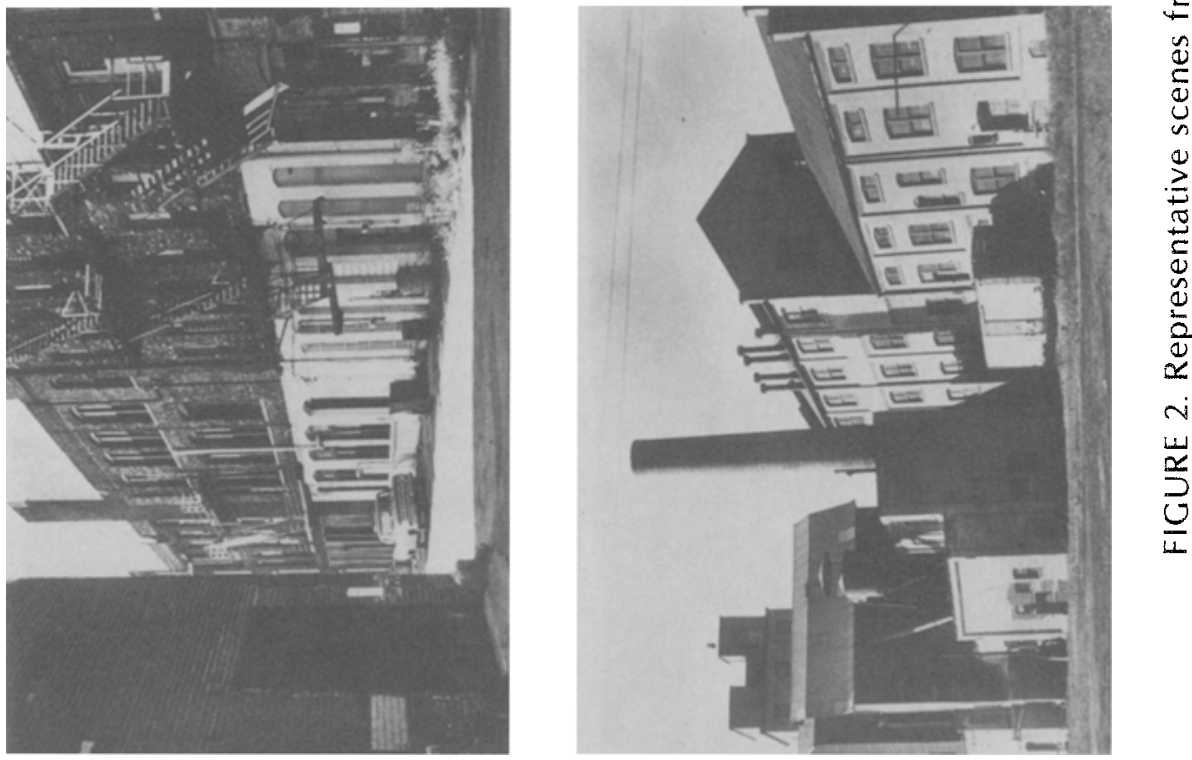
THOMAS R. HERZOG, STEPHEN KAPLAN AND RACHEL KAPLAN
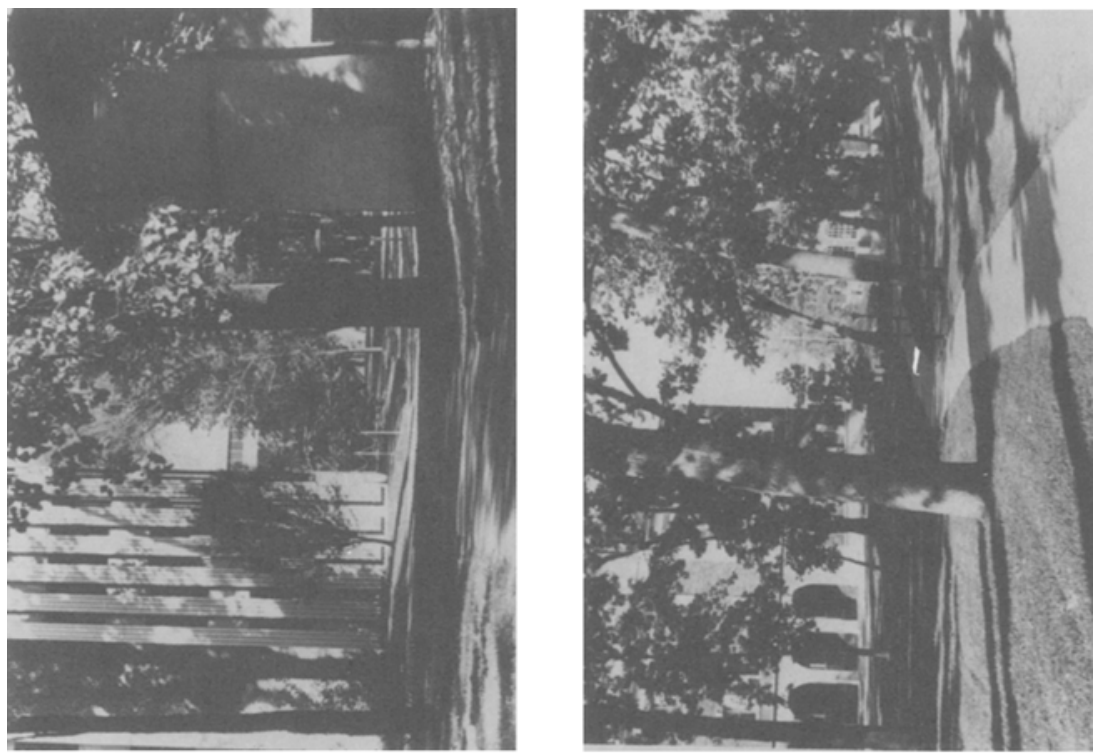

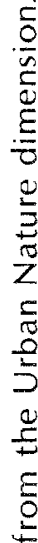
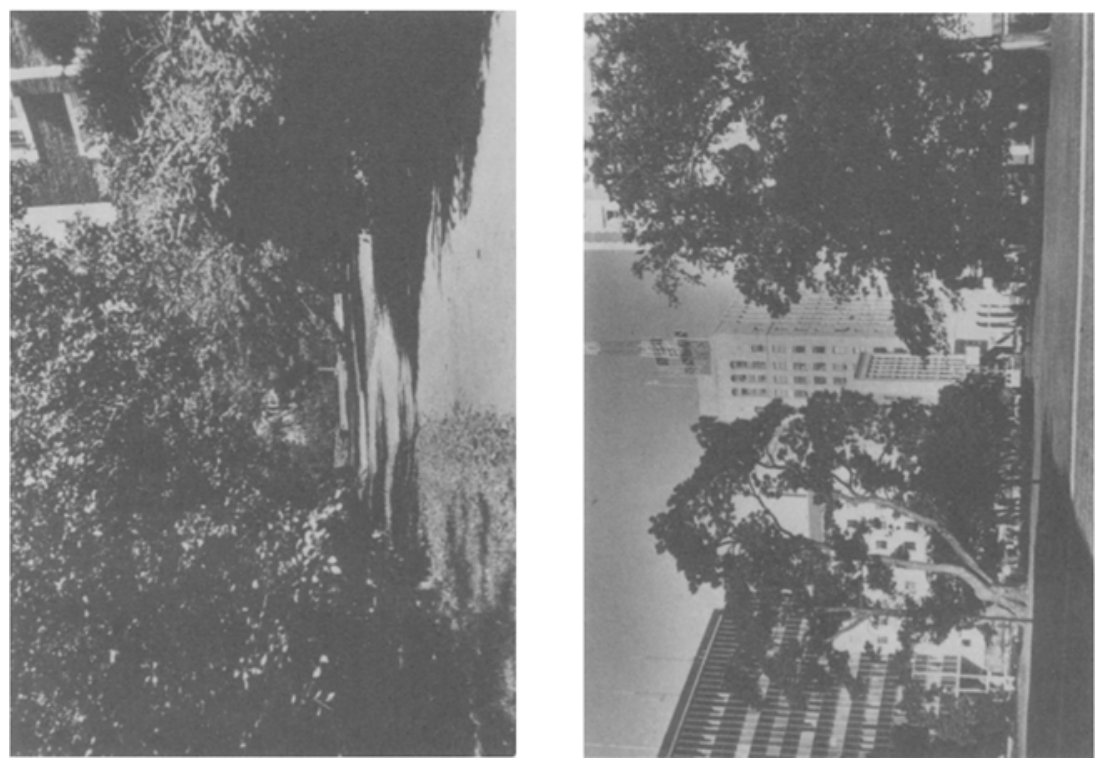

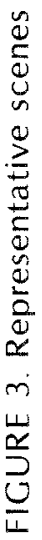


POPULATION AND ENVIRONMENT
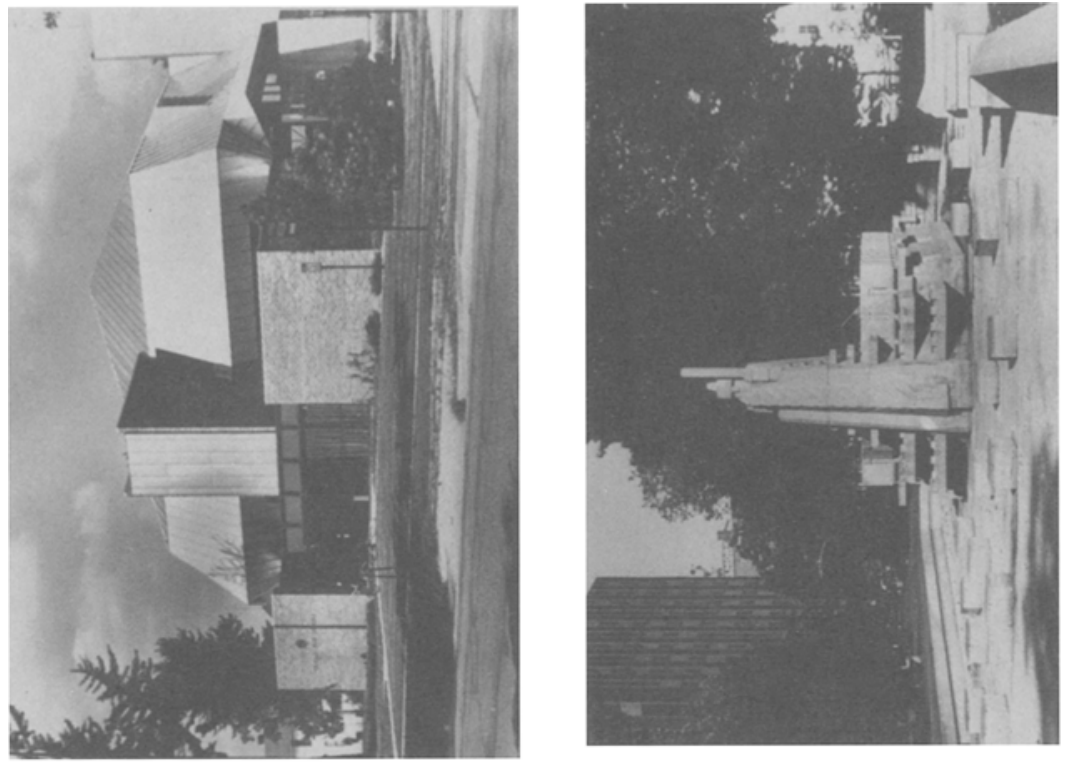

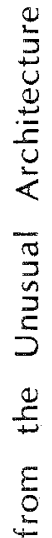
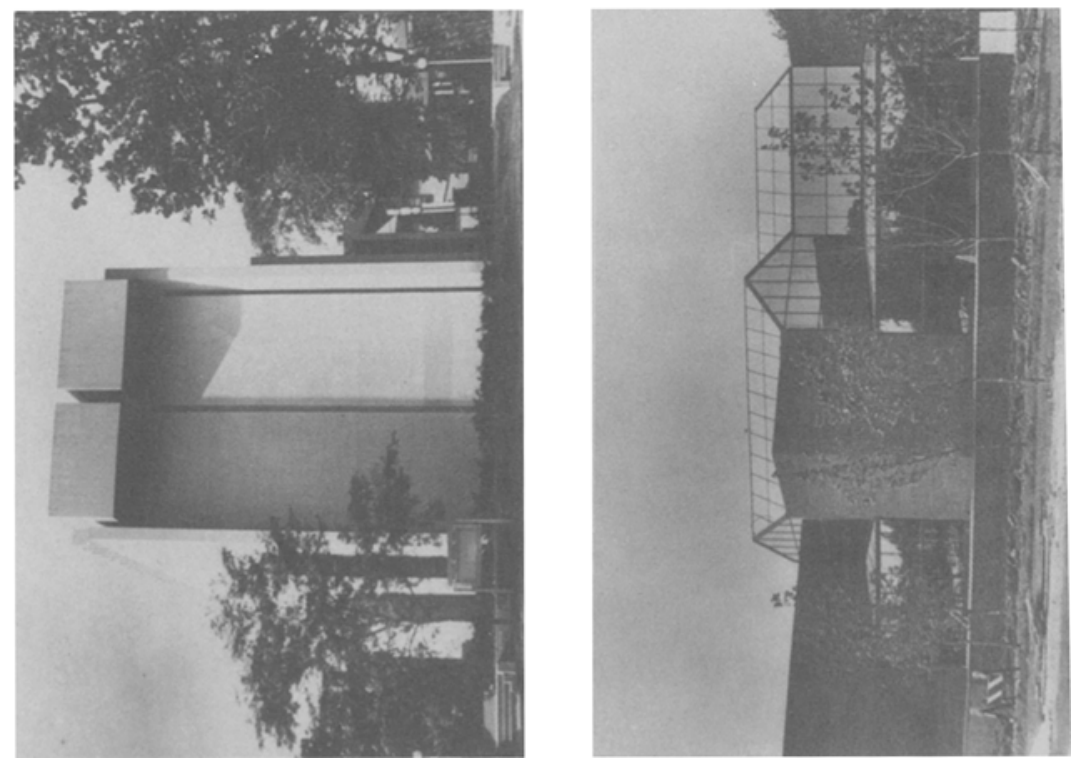

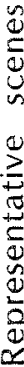

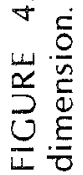


The fourth dimension included six scenes (Figure 4) each of which represented a rather striking architectural achievement. This was called the Unusual Architecture dimension.

The fifth dimension consisted of six relatively large, older buildings (Figure 5). They varied widely in function and appearance. They were not run-down or neglected, just relatively older. Hence, the dimension was named Older Buildings.

As in prior studies, the basis for categorization of the urban environment does not follow the purely functional lines suggested by the planners' emphasis on land use. Rather, other factors, especially age, also play a role. In Herzog et al. (1976), older buildings and contemporary ones formed separate groupings; here again, relatively modern buildings and older ones clustered in different categories. The obtained categories thus provide some fascinating and perhaps unexpected hints as to what the important distinctions are in an urban setting.

\section{The Prediction of Preference}

Role of content. As Table 1 shows, the mean preferences for the five urban categories were strikingly different $(F=265.92$, $\mathrm{df}=4 \& 564, \mathrm{p}<.001)$. Subsequent tests revealed that each category differed from all others ( $p$ <.001) except for Unusual Architecture and Older Buildings which were tied for second place. The Urban Nature category was by far the most preferred. Following Unusual Architecture and Older Buildings was Contemporary Life, almost a full scale point lower than Urban Nature, and finally the Alley/Factory cluster, a full scale point lower than Contemporary Life.

It is clear from these results that content has a strong impact on preference. Several specific issues, based on the preference means, would certainly seem worthy of further investigation. First, people seem to have only a modest enthusiasm for unusual architecture. If this result can be replicated, it suggests that designing primarily for novelty may be equivalent to designing for indifference. The resulting design will be neither strongly liked nor disliked.

Second, alleys and factories are distinctly disliked. This has interesting implications in terms of the possibility that there is a link between preference for a particular environment and what that environment affords. S. Kaplan (1979b) has proposed that human preference might constitute a quick evaluative summary of the appropriateness of a given environment for the support of human life. In a study that looked at the capacity of former mental 
POPULATION AND ENVIRONMENT
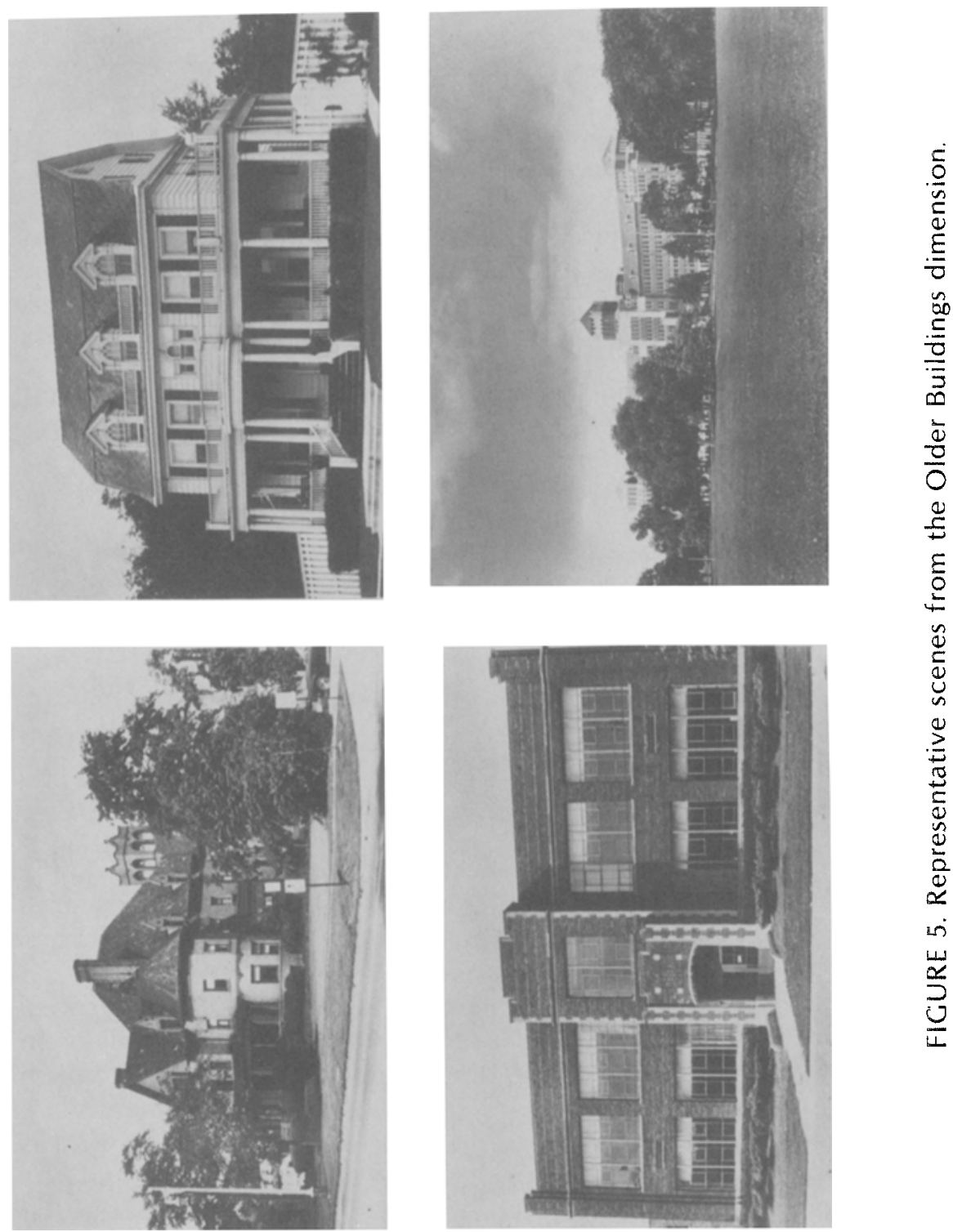
THOMAS R. HERZOG, STEPHEN KAPLAN AND RACHEL KAPLAN

Table 1

Mean Ratings for Each Variable and Content Domain

\begin{tabular}{|c|c|c|c|c|c|c|}
\hline \multirow[b]{2}{*}{ Variables } & \multicolumn{5}{|c|}{ Content Domain } & \multirow[b]{2}{*}{ Nean } \\
\hline & $\begin{array}{l}\text { Contemporary } \\
\text { Life }\end{array}$ & $\begin{array}{l}\text { Alley/ } \\
\text { Factory }\end{array}$ & $\begin{array}{l}\text { Urbon } \\
\text { Nature }\end{array}$ & $\begin{array}{l}\text { Unusual } \\
\text { Arenitecture }\end{array}$ & $\begin{array}{l}\text { Clder } \\
\text { Buildings }\end{array}$ & \\
\hline \multicolumn{7}{|l|}{ Preference } \\
\hline 15 sec & 2.66 & 1.64 & 3.56 & 3.16 & 3.14 & 2.83 \\
\hline $20 \mathrm{msec}$ & 2.86 & 1.91 & 3.80 & 3.39 & 3.20 & 3.03 \\
\hline $2 \times 10 \mathrm{msec}$ & 2.94 & 1.62 & 3.74 & 3.36 & 3.14 & 2.96 \\
\hline $10 \mathrm{msec}$ & 2.67 & 1.76 & 3.93 & 3.27 & 3.28 & 2.98 \\
\hline Nean & 2.74 & 1.69 & 3.69 & 3.25 & 3.17 & \\
\hline Identifiability & 3.30 & 2.95 & 2.44 & 2.36 & 3.14 & \\
\hline Conerence & 3.44 & 2.41 & 2.48 & 3.45 & 3.56 & \\
\hline Complexity & 3.01 & 3.68 & 3.03 & 3.28 & 3.05 & \\
\hline Mystery & 2.65 & 3.28 & 4.02 & 2.92 & 2.51 & \\
\hline
\end{tabular}

patients to function outside the hospital, Smith (1976) has found evidence that for these individuals the commercial/industrial region was in fact not health-enhancing. Substantially more individuals in these areas found it necessary to return to the hospital.

Third, nature in the city appears to be highly valued. This is not only expressed in the preference level of the most preferred category, but it also functions across all of the scenes used in this study. An analysis of the number of scenes showing substantial foliage indicates that 71 percent of the most-preferred scenes (in the top quartile) include this. In the next quartile, only 44 percent of the scenes show considerable foliage, and in the remaining two quartiles these percentages are 11 and zero! Seven of the nine Urban Nature scenes are included in the top quartile, and 10 of the 11 Alley/Factory scenes are in the lowest quartile. Certainly vegetation is not necessarily incompatible with the kinds of scenes showing least preference. Here is a way in which the urban landscape might easily be improved.

Predictor variables. The predictor variables can be analyzed in two quite different ways which provide differing perspectives on their effects. On the one hand, one can look at the means of each of the predictors across the urban categories. These means are given in the bottom portion of Table 1 . On the other hand, it is useful to explore the relationship between preference and the predictor variables within each urban category. In this case the results must be viewed cautiously as they necessarily rely upon rather small samples, namely the number of stimuli in each 
category. For these correlational analyses the criterion variable was the mean preference obtained in the 15 -second condition. Only correlations significant at $p<.05$ are reported, which, given the small number of stimuli, requires relatively large correlations.

From the results of these two analytic approaches, it appears that the predictor variables have some interesting relationships to preference. For example, the urban category that was both low in coherence and highest in complexity (i.e., Alley/Factory) was also the least preferred. This squares with the suggestion of several theorists (e.g., Lynch, 1960; Milgram, 1970) that massive doses of unstructured information will not be appreciated. Within the Alley/Factory category, coherence was a positive predictor of preference $(r=.61)$. Thus, even though these scenes were low in both coherence and preference, those that were relatively more coherent were better liked. In confusing environments, a little structure is welcomed. Within the Alley/Factory category, the scenes that were relatively more coherent and better liked tended to be the alley scenes. By contrast, the factory scenes were by far the least liked scenes of all and tended to be lower in identifiability than the alley scenes. This led to a negative correlation between identifiability and preference within the Alley/Factory category $(\mathrm{r}=-.79)$ :

As Table 1 shows, the ratings of mystery were high only for the most preferred Urban Nature category. Although the association between mystery and nature content was expected from previous research ( $R$. Kaplan, 1975), it is well to remember that here the category clearly represented urban nature. This raises the possibility that, as Cullen (1961) suggested in Townscape, mystery could be a powerful factor in the urban scene. Alexander, Ishikawa, and Silverstein (1977), in a stimulating book entitled $A$ Pattern Language, also support this possibility. Clearly, a study of non-nature-related mystery in the urban environment is called for.

The last finding of interest involving a predictor variable occurred within the Unusual Architecture category. For this category, the most preferred scenes were also the most identifiable $(r=81)$. This finding suggests the importance of being able to make sense of new elements in the urban environment. As S. Kaplan (1975) pointed out in introducing this concept, the frustration that is reflected by the absence of identifiability suggests that advocating ambiguity as a desirable feature of the designed environment may be ill-advised. 


\section{Effects of Viewing Time}

It is clear that the reactions to these urban settings reflect a highly complex underlying cognitive structure. Preference must be the outcome of an integration of many diverse factors. This raises the question of how long it takes to come up with this sort of judgment. Was the 15 seconds used in Herzog et al. (1976) necessary? Given the fleeting glances that more often characterize people's commerce with the urban environment, would the preferences have been strikingly different with shorter viewing times? In other words, is a study based on a 15-second viewing time valid as far as real world applications are concerned? The present study provides a clear answer to this question.

As Table 1 shows, the overall preference means for the viewing times are very similar. Statistical analysis revealed no differences among the three short-duration conditions, but the average preference rating for the short durations combined was significantly higher than the mean in the 15-second condition $(t=2.34, d f=141, p<.025)$. These results partially support $R$. Kaplan's (1975) findings which also showed no notable differences in preference among the short duration intervals (ranging from 10 to 200 milliseconds). The slight but significant preference reduction in the 15-second condition may well have been caused by the onset of boredom. In the $2 \times 10$-millisecond condition, some participants did not bother to look at the second 10 -millisecond presentation before making their ratings. Evidently they were able to see everything they wanted to see even with the briefest viewing time. More to the point as regards the validity of the 15-second condition, there was no difference in the pattern of preference means across urban categories for the four viewing times (i.e., the interaction of viewing time and urban category did not even remotely approach statistical significance; $F=.90, \mathrm{df}=12 \& 564$ ). This means that a 15 -second viewing time provides valid data for relative comparisons of preference across urban categories.

\section{IMPLICATIONS}

This study describes a methodology that could be used to incorporate public input into the planning process. At the same time it indicates one reason why doing so could make a positive 
POPULATION AND ENVIRONMENT

contribution: The results suggest a number of ways in which citizens' perceptions and preferences differ from those of planners. This is consistent with other studies (e.g., Anderson, 1978; Langer \& Imber, 1979) that point to important differences between experts and non-experts. Studies of this kind could be carried out in various cities, helping planners to achieve a better understanding of how citizens view their environment and what they most value. In addition, such studies could provide a basis of comparison across different cities. In this way one could determine those categories of urban experience that are widely shared and those that are unique to a particular city or region.

In addition to these rather general perspectives, there are a number of more specific findings in this study that suggest potentially useful directions for the planning process:

1. Natural features figure prominently in preference and should be considered in any redevelopment efforts.

2. Striking architecture is substantially more appreciated when it is identifiable.

3. Age-as well as land use - is an important factor in people's perception of the urban scene.

4. Mystery should be explored for its possible role in increasing preference in urban environments.

5. High complexity urban areas must also be highly coherent to retain a satisfactory visual quality.

\section{REFERENCES}

Alexander, C., Ishikawa, 5., \& Silverstein, M. A pattern language. New York: Oxford University Press, 1977.

Anderson, E. Visual resource assessment: Local perceptions of familiar natural environments. Doctoral dissertation. University of Michigan. 1978.

Appleyard, D. Notes on urban perception and knowledge. Paper presented at the Environmental Design Research Association (EDRA) Conference, Pittsburgh, 1970.

Bruner, J.S. On perceptual readiness. Psychological Review, 1957, 64, 123-152.

Craik, K.H. Environmental psychology. In P.H. Mussen and R. Rosenzweig (Eds.). Annual review of psychology. Palo Alto, California: Annual Reviews, Inc., 1973, pp. 403-422.

Cullen, G. Townscape. New York: Reinhold, 1961.

Downs, R.M., \& Stea, D. Maps in minds: Reflections on cognitive mapping. New York: Harper \& Row, 1977.

Downs, R.M., \& Stea, D. Image and environment. Chicago: Aldine, 1973.

Herzog, T.R., Kaplan, S., \& Kaplan, R. The prediction of preference for familiar urban places. Environment and Behavior, 1976, 8, 627-645.

Kaplan, R. Down by the riverside: Informational factors in waterscape preference. In River recreation management and research symposium. USDA Forest Service General Technical Report NC-28, 1977, pp. 285-289 
THOMAS R. HERZOG, STEPHEN KAPLAN AND RACHEL KAPLAN

Kaplan, R. Some methods and strategies in the prediction of preference. In E.H. Zube, R.O. Brush, and J.G. Fabos (Eds.), Landscape assessment: Values, perceptions, and resources. Stroudsburg, $\mathrm{Pa}_{\mathrm{a}}$ : Dowden, Hutchinson \& Ross, 1975, pp. 118-129.

Kaplan, R. A strategy for dimensional analysis. In D.H. Carson (Ed.), Man-environment interactions. Environmental Design Research Association Proceedings, Part 9. 1974, pp. 66-68.

Kaplan, $R$. The dimension of the visual environment: Methodological considerations. In W.J. Mitchell (Ed.), Environmental design: Research and practice. Proceedings of the Environmental Design Research Association Conference Three, Los Angeles, 1972.

Kaplan, S. Concerning the power of content-identifying methodologies. In T.C. Daniel and E.H. Zube (Eds.). Assessment of amenity resource values. USDA Forest Service Rocky Mountain Station, 1979. (a)

Kaplan, S. Perception and landscape: Conceptions and misconceptions. Proceedings of our national landscape conference. USDA Forest Service General Technical Report TSW-35. 1979, pp. 241-248. (b)

Kaplan, S. An informal model for the prediction of preference. In E. H. Zube, R.O. Brush, and J.G. Fabos (Eds.). Landscape assessment: Values, perceptions, and resources. Stroudsburg, $\mathrm{Pa}$.: Dowden, Hutchinson \& Ross, 1975, pp. 92-101.

Kaplan, S., \& Kaplan, R. (Eds.). Humanscape: Environments for people. Belmont, Ca: Duxbury (Division of Wadsworth), 1978.

Langer, E.J., \& Imber, L.G. When practice makes perfect: Debilitating effects of overlearning. Journal of Personality and Social Psychology, 1979, 37, 2014-2024.

Lingoes, I.C. A general survey of the Guttman-Lingoes nonmetric program series. In R.N. Shepard, A.K. Romney, and S.B. Nerlove (Eds.), Multidimensional scaling, Volume

1. New York: Seminar Press, 1972, pp. 52-68.

Lynch, K. The image of the city. Cambridge, Mass.: MIT Press, 1960.

Milgram, S. The experience of living in cities. Science, 1970, 167, 1461-1468.

Parr, A.E. City and psyche. Yale Review, 1965, 55, 71-85.

Smith, C.). The geography of mental health. Association of American Ceographers Resource Paper No. 76-4, 1976. 